\title{
Corrigendum: Variation in Coral Thermotolerance Across a Pollution Gradient Erodes as Coral Symbionts Shift to More Heat-Tolerant Genera
}

\begin{abstract}
Melissa S. Naugle ${ }^{1,2 *}$, Thomas A. Oliver ${ }^{3}$, Daniel J. Barshis ${ }^{4}$, Ruth D. Gates ${ }^{5 \dagger}$ and Cheryl A. Logan ${ }^{1}$

1 Department of Marine Science, California State University, Monterey Bay, Seaside, CA, United States, ${ }^{2}$ Moss Landing Marine Laboratories, Moss Landing, CA, United States, ${ }^{3}$ National Oceanic and Atmospheric Administration, Pacific Island Fisheries Science Center, Honolulu, HI, United States, ${ }^{4}$ Department of Biological Sciences, Old Dominion University, Norfolk, VA, United States, ${ }^{5}$ Hawai'i Institute of Marine Biology, University of Hawai'i at Mānoa, Kāne'ohe, HI, United States
\end{abstract}

Keywords: coral reefs, pollution, gene expression, symbiosis, phenotypic plasticity, climate change, thermal tolerance, acclimatization

\section{A Corrigendum on}

Variation in Coral Thermotolerance Across a Pollution Gradient Erodes as Coral Symbionts Shift to More Heat-Tolerant Genera

by Naugle, M. S., Oliver, T. A., Barshis, D. J., Gates, R. D., and Logan, C. A. (2021). Front. Mar. Sci. 8:760891. doi: 10.3389/fmars.2021.760891

In the original article, the authors neglected to include an additional funder: a California State University Council on Ocean Affairs, Science \& Technology (COAST) grant to MN. The updated Funding statement appears below:

"The 2014 component of this project was funded by a National Oceanic and Atmospheric Administration Coral Reef Conservation Program grant to TO, RG, and CL (NA13NOS4820018). Data collection and analysis in 2019 was funded by a California State University, Monterey Bay Research, Scholarship and Creative Activity grant to CL, an Earl H. and Ethel M. Myer's Oceanographic and Marine Biology Trust grant to MN, a California State University Program for Education and Research in Biotechnology grant to MN, an Explorer's Club-Mamont Scholar grant to MN, and a California State University Council on Ocean Affairs, Science \& Technology (COAST) grant to MN."

The authors apologize for this error and state that this does not change the scientific conclusions of the article in any way. The original article has been updated. Accepted: 13 December 2021

Published: 05 January 2022

Citation:

Naugle MS, Oliver TA, Barshis DJ,

Gates RD and Logan CA (2022)

Corrigendum: Variation in Coral Thermotolerance Across a Pollution Gradient Erodes as Coral Symbionts Shift to More Heat-Tolerant Genera.

Front. Mar. Sci. 8:833194.

doi: 10.3389/fmars.2021.833194
Publisher's Note: All claims expressed in this article are solely those of the authors and do not necessarily represent those of their affiliated organizations, or those of the publisher, the editors and the reviewers. Any product that may be evaluated in this article, or claim that may be made by its manufacturer, is not guaranteed or endorsed by the publisher.

Copyright (๑) 2022 Naugle, Oliver, Barshis, Gates and Logan. This is an open-access article distributed under the terms of the Creative Commons Attribution License (CC BY). The use, distribution or reproduction in other forums is permitted, provided the original author(s) and the copyright owner(s) are credited and that the original publication in this journal is cited, in accordance with accepted academic practice. No use, distribution or reproduction is permitted which does not comply with these terms. 